Article

\title{
The Methods and Techniques of Strategic Environmental Assessment. Comparative Evaluation of Greek and International Experience
}

\author{
Antonios Souloutzoglou * (D) and Anastasia Tasopoulou \\ Postgraduate Programme “The Technologies of Environmental Legislation”, Department of Environmental \\ Engineering, Democritus University of Thrace, 67100 Xanthi, Greece; ntasopo@yahoo.gr \\ * Correspondence: anton-soul@hotmail.com
}

Received: 15 March 2020; Accepted: 16 April 2020; Published: 18 April 2020

check for updates

\begin{abstract}
Strategic Environmental Assessment (SEA) is a process used for the evaluation of environmental impacts at a higher level of decision-making than that of each individual project, i.e., during the preparation and implementation of policies, programs, and plans, with the objective of incorporating the aspect of sustainable development in the early stages of planning. However, the "strategic" nature of SEA is the cause of frequent confusion among the responsible competent institutions and professionals regarding the selection of the most appropriate methods and techniques for each individual situation. At the international level, current research indicates a certain ambiguity in the use of methods and techniques in every step of SEA processes. In Greece, despite the implementation of SEA procedures in the preparation of a number of plans and programs after the transposal of the SEA Directive, to date, no attempt has been made to systematize the current experience and practice from the utilization of methods and techniques. The objective of the present study is to analyze and provide a comparative evaluation of the Greek and international experience, on the one hand with the systematic examination of Strategic Environmental Impact Assessments, and on the other with primary research, through questionnaires addressed to Greek practitioners. An important observation is that, both in Greece and abroad, there are inadequacies in the existence and/or the use of guidance manuals for the selection of the most appropriate methods and techniques, and only a limited range of methods and techniques are used in comparison with those catalogued in international literature.
\end{abstract}

Keywords: strategic environmental assessment; strategic environmental impact assessment; methods; techniques; Greece

\section{Introduction}

Strategic Environmental Assessment (SEA) is a relatively recent environmental process, having made its debut roughly 30 years ago in countries such as the USA and Canada, and international organizations, such as the World Bank, with the objective of transitioning from the "polluter pays" principle to that of prevention [1]. It is, in essence, a process that aims to incorporate the environmental aspect both prior to and during the designing of policies, plans, and programs (PPPs). This integration produces environmentally sound strategies, with a resultant increase in the certainty that any projects and operations which will subsequently be adopted, as well as any other form of general environmental intervention, will not be harmful [2].

SEA requires an exact process, and a defined arrangement of procedures. This process was gradually integrated in a number of states. In Europe, SEA procedures were comprehensively debated and adopted by the European Parliament and Council in July 2001, with Directive 2001/42/EC 
(SEA Directive). This directive was transposed significantly later into Hellenic environmental law, in August 2006, with the Joint Ministerial Decision MEPPPW/SES/10717/28.08.2006 (SEA JMD), which was later amended by the Ministerial Decision 40238/2017. Furthermore, the required procedures include the description of the current status of the environment, the examination of alternatives, the identification, description, and evaluation of any significant environmental effects, the integration of the results of the environmental assessment and public consultation into the plan or program under approval. and finally, the monitoring of any future impacts stemming from their implementation.

The aforementioned series of procedures is carried out through the use of various methods and techniques. However, international literature finds confusion between the terms methods and techniques, as many researchers and authors consider them synonymous. Typical examples of this are the Geographic Information Systems (GIS). Both Noble and Storey [3] and Therivel [4] agree that GIS are used for the collection, management, classification, and presentation of data, however, the first authors classify them into methods, while Therivel classifies them into techniques.

Many of these methods and techniques, over 350, are cited in international literature, according to Lee [5]. In particular, certain simple methods and techniques, which do not require specialized equipment and quantitative records, have been documented, an example of such being expert judgment. On the other hand, there are methods and techniques which provide adequate levels of accuracy in their results, through the use of specialized software and quantitative records, such as GIS, while those which utilize matrices for the documentation and evaluation of impacts are also quite widespread. However, the terms "methods" and "techniques" are often conflated, with many practitioners and authors considering them to be synonymous. Their differentiation is down to the fact that techniques provide data, while by contrast, methods relate to the identification and description of possible impacts, as well as the compilation and classification of data [3].

Despite the fact that individual SEA methodologies are provided by the existing legislative frameworks, including a number of activities, there are no universal methods and techniques adhered to by all participating parties. In general terms, SEA methods were drawn from those utilized in both Environmental Impact Assessment (EIA) surveys, and in policy and planning analysis methods. The ambiguity surrounding SEA, according to Noble et al. [6], which is due exactly to its "strategic" nature, is often the cause of confusion among the responsible competent institutions and practitioners regarding the selection of the most appropriate methods and techniques for each individual situation; this results in only a limited number ultimately being utilized. Furthermore, individual methods and techniques are utilized on a greater scale and at more steps of SEA.

In Greece, SEA processes have been implemented in the preparation of a number of plans and programs following the transposal of the SEA Directive. Zagorianakos [7], by conducting an ex-ante appraisal of the implementation of SEA Directive, came to the conclusion that a series of methodological, institutional, political, and legislative problems in Greece make the implementation of the SEA Directive rather problematic. Subsequently, the evaluation of the degree of application of some key features of the SEA during the transport planning process in the Athens Olympics in 2004 demonstrated that the methodological and procedural flexibility of the SEA is the key to its implementation in countries wherein the environmental assessment of strategic actions is either absent or underdeveloped [8]. However, no surveys or studies have been carried out as of yet in order to systematize the existing experience and practice from the development of methods and techniques during SEA processes.

The present study discusses the research and analysis of the methods and techniques applied during the SEA process. This analysis is not carried out independently, however; firstly, a correlation is made between the methods and techniques, and the existing experience and practice, both in Greece and abroad. Furthermore, a comparative assessment of the international and Greek experience is carried out in order to discern similarities and differences regarding the adoption and utilization of the methods and techniques. 


\section{Background}

SEA procedures have been widely adopted worldwide, without this necessarily meaning that we are leading to a convergence as regards the legislative framework or the means used between states, due to the variety of legal, cultural, and institutional contexts. Based on the existing literature, the present section seeks to provide insight into SEA identity, institutional framework and its application on a global level, bringing the European experience into focus, and followed by a brief analysis of the position of SEA in the Hellenic Environmental Law. Consequently, an overview of the SEA methodological approach is attempted, and the most frequent methods and techniques used in the relevant procedures are identified and systematized.

\subsection{Identity and International Institutional SEA Framework}

Numerous definitions have been offered in international literature for SEA, by researchers who have studied both its theory and practice. The most comprehensive of these was formulated by Partidario [9] (p. 19), according to whom, "SEA is a systematic, on-going process for evaluating, at the earliest appropriate stage of publicly accountable decision-making, the environmental quality, and consequences, of alternative visions and development intentions incorporated in policy, planning, or programme initiatives, ensuring full integration of relevant biophysical, economic, social and political considerations". Essentially, SEA is utilized at the international level in order to assess environmental impacts during planning, at a higher level than that of the project in question, i.e., during the preparation and enactment of PPPs with the objective of integrating the aspect of sustainable development at an early stage of planning.

The widespread adoption of SEA procedures, which have been included in the legal framework of roughly 60 states, directly correlates with the increased understanding of the relationship between development and the environment [10]. It was initially connected with the expansion of procedures and practices utilized within the context of EIA projects at higher levels of decision-making [11], while, primarily in recent years, gradual efforts have been made for the reinforcement of its "strategic" approach [12].

The primary attributes of SEA, according to Sadler and Verheem [13] are:

1. Assurance that the necessary attention is given to the environmental aspect in the development of PPPs.

2. Reinforcement and improvement of EIA at project level.

3. Enablement of definition and organization of cumulative impacts.

4. Promotion of sustainable development.

5. Promotion of consultation among various governmental bodies and interested parties, and increase of public participation in the configuration of PPPs.

In 1969, the USA was the first state to enact legislation incorporating EIA procedures through the National Environmental Policy Act (NEPA). The NEPA also includes provisions for the assessment of environmental impacts at the strategic or extra-project level, a procedure titled Programmatic Environmental Impact Statement (PEIS) [1]. At the UN level, the United Nations Economic Commission for Europe ratified the SEA Protocol, within the framework of the Fifth Ministerial Conference "Environment for Europe", which was held in Kiev, Ukraine, in May 2003. The protocol came into effect on 21 July 2010, and has been ratified by the EU and 32 other nations [14].

On the other hand, in the European Union (EU), the Habitats Directive (92/43/EEC) was the Directive that required the assessment of potential environmental impacts before the approval of the implementation of the plan or project on Natura 2000 sites [15]. However, there was no comprehensive legislative framework to incorporate the environmental aspect at the PPP level until 2001. The first institutionalized assessments of environmental impacts pertained to the project level were through Directives 85/337/EEC and 97/11/EC (EIA Directives). The European Commission submitted three reports (in 1993, 1997, and 2003) to the European Parliament regarding their implementation and 
effectiveness. The common conclusion of all three of these reports was that, despite the significant progress which had been achieved by the member states regarding their implementation, high-level environmental protection remained a desideratum.

It thus became apparent that, in order to achieve effective, high-level environmental protection over time, the environmental aspect needed to be integrated into the higher levels of decision making, which established the framework for subsequent permits regarding the execution of projects, i.e., at the level of strategic planning of policies, drafting, and programming [16]. However, the lack of a comprehensive institutional SEA framework provided an incentive for certain member states to adopt such systems in the 1980s and 1990s [4]. Regardless, the utilization of a variety of different procedures demonstrated the need for adoption of a comprehensive institutional SEA framework at the EU level, leading to the submission of a preliminary proposal for discussion by the European Commission in 1990 [17]. The publication of the official proposal from the European Commission was submitted in December 1996, and it became the subject of in-depth debate. It was ultimately adopted in July 2001 as Directive 2001/42/EC. Table 1 presents the SEA steps and outputs, according to Thérivel [4].

Table 1. Strategic Environmental Assessment (SEA) steps and outputs [4].

\begin{tabular}{|c|c|c|c|}
\hline No & SEA Step & What to Decide & What to Record \\
\hline 1 & $\begin{array}{l}\text { Identify SEA objectives, indicators, } \\
\text { and targets }\end{array}$ & $\begin{array}{l}\text { What environmental and } \\
\text { sustainability objectives, } \\
\text { targets, and/or indicators to } \\
\text { test the plan options and } \\
\text { statements against }\end{array}$ & $\begin{array}{l}\text { List of SEA objectives, indicators, } \\
\text { and targets where relevant }\end{array}$ \\
\hline 2 & $\begin{array}{l}\text { Describe environmental baseline, } \\
\text { including future trends; identify } \\
\text { environmental issues and problems }\end{array}$ & $\begin{array}{l}\text { What environmental and } \\
\text { sustainability issues and } \\
\text { constraints to consider during } \\
\text { decision-making }\end{array}$ & $\begin{array}{l}\text { Data on the baseline environment; } \\
\text { list of relevant environmental and } \\
\text { sustainability issues and constraints }\end{array}$ \\
\hline 3 & $\begin{array}{l}\text { Identify links to other relevant } \\
\text { strategic actions }\end{array}$ & $\begin{array}{l}\text { What other strategic actions } \\
\text { influence the strategic action } \\
\text { in question, and how }\end{array}$ & $\begin{array}{l}\text { List of relevant strategic actions, } \\
\text { their requirements, and any } \\
\text { constraints or conflicts with the } \\
\text { strategic action in question }\end{array}$ \\
\hline 4 & $\begin{array}{l}\text { Identify (more) sustainable } \\
\text { alternatives for dealing with the } \\
\text { problems and implementing the } \\
\text { strategic action objective }\end{array}$ & $\begin{array}{l}\text { What alternatives or options to } \\
\text { consider }\end{array}$ & List of alternatives or options \\
\hline 5 & Prepare Scoping Report; consult & $\begin{array}{l}\text { What to include in the Scoping } \\
\text { Report }\end{array}$ & $\begin{array}{l}\text { Results of steps 1-4; agreed written } \\
\text { statement of how to proceed with } \\
\text { subsequent SEA steps }\end{array}$ \\
\hline 6 & $\begin{array}{l}\text { Predict and evaluate impact of } \\
\text { alternatives/statements; compare } \\
\text { alternatives; mitigate impacts of } \\
\text { chosen alternative(s)/statements }\end{array}$ & $\begin{array}{l}\text { What are the effects of the } \\
\text { alternatives/options and } \\
\text { statements on the } \\
\text { environmental/sustainability } \\
\text { objectives and indicators; what } \\
\text { are the preferred alternatives; } \\
\text { what mitigation measures to } \\
\text { include }\end{array}$ & $\begin{array}{l}\text { Summary of effects of } \\
\text { alternatives/options and statements } \\
\text { on the environment and } \\
\text { sustainability; list of preferred } \\
\text { alternatives; explanation of why } \\
\text { these are preferred; mitigation } \\
\text { measures proposed }\end{array}$ \\
\hline 7 & $\begin{array}{l}\text { Write the SEA report; establish } \\
\text { guidelines for implementation }\end{array}$ & $\begin{array}{l}\text { How to present the data from } \\
\text { steps 1-6 }\end{array}$ & Prepare the SEA report \\
\hline 8 & Consult & $\begin{array}{l}\text { Whom to consult; how to } \\
\text { respond to consultation results }\end{array}$ & $\begin{array}{l}\text { How consultation results were } \\
\text { addressed }\end{array}$ \\
\hline 9 & $\begin{array}{c}\text { Monitor the } \\
\text { environmental/sustainability } \\
\text { impacts of the strategic action }\end{array}$ & $\begin{array}{l}\text { How to deal with any negative } \\
\text { impacts of the strategic action }\end{array}$ & $\begin{array}{c}\text { How the strategic action's impacts } \\
\text { will be monitored and significant } \\
\text { effects dealt with }\end{array}$ \\
\hline
\end{tabular}

Several authors have conducted research on the SEAs legislative framework, its application and effectiveness in areas such as urban planning in Italy and in Spain [18-26]. Specifically, Spain has incorporated the SEA Directive through the Law 9/2006, which was later replaced by the Law 21/2013, and more recently by the Law $9 / 2018$. The latest was a medium to drive significant changes that have been made to the SEA processes in order to ensure the protection of Natura 2000 sites [18]. It is 
important to highlight the specific differentiation of the authority that is responsible for developing and adopting the plan or program and the relevant authority that is responsible for assessing the environmental impacts of the proposed plan or program [26].

In the case of Italy, the SEA Directive was incorporated into Italian law by national decree 152/2006, and amended in 2008 and 2010. The distinctive characteristic of the Italian system is the regional diversification of SEA procedures due to the legal provisions varying between regions [26]. However, due to the inadequacy of existing legislation, the regional legislative framework has only complied with the minimum requirements of the European directive, along with the Italian national decree [19]. Notwithstanding this shortcoming, SEA has gradually introduced concepts such as carrying capacity and resilience at the planning stage. Simultaneously, it is also leading to progress of public consultation and decision makers' accountability [25].

In summary, the SEA legislative framework constitutes a perpetually developing process worldwide, with the objective of environmental assessment, evaluation, and management of the environmental impacts of human activity. This development does not necessarily result in the convergence and integration of SEA procedures between states. The differing approaches, which have been and continue to be developed, are due to the divergent, among others, legal, political, cultural, and institutional frameworks of each state. Chacker et al. [27], after comparing the implementation of SEA in 12 selected countries, discovered, despite the noted variety in procedures, the existence of significant similarities:

1. The procedures for determining screening (field of application) as well as scoping (extent and magnitude of application) are legally binding.

2. In the majority of countries, the content of SEA pertains to the assessment of the environmental impacts of strategic proposals.

3. The development of an environmental report is a prerequisite in all the states examined by the study.

4. Almost all of the studied countries require the consideration of alternatives.

5. The majority of countries require both impact mitigation and monitoring measures.

6. Public participation is an integral element of the entirety of the SEA systems.

7. Qualitative assurance of SEA is required in all systems, with the exception of Canada, Denmark, and New Zealand.

\subsection{SEA in Hellenic Environmental Law}

Before the transposal of the SEA Directive, there were no official procedures in place in Hellenic environmental law for the implementation of SEA procedures during the preparation of plans and programs [28]. The evaluation of environmental impacts was limited to the assessment of projects and activities through EIA. The absence of environmental protection provisions at the initial planning stages was characteristic in the case of plans or programs of a strategic nature, such as the construction of the Egnatia Motorway. However, in the relevant Hellenic literature, certain projects of wide scope and extent have been documented, which incorporated procedures similar to SEA in the drafting of the corresponding EIA reports [28,29]. One such notable example was the EIA report on the installations put into place for the Athens Olympics in 2004. 
However, despite the existence of this specific legal gap, and the explicit wording of the SEA Directive that "Member states shall bring into force the laws, regulations and administrative provisions necessary to comply with this directive before 21 July 2004" (Article 13, L197/34), it was transposed into Hellenic law two years after the deadline (no. MEPPPW/SES/107017/28.08.2006 JMD and its amendment with MD 40238/2017). The competent authority for the supervision, evaluation, processing, and approval of the preliminary environmental screening and environmental report (SEIA) of the SEA is the Directorate of Environmental Licensing. This authority belongs to the Ministry of the Environment and Energy. The SEA is defined, according to this Joint Ministerial Decision, as the procedure for assessment of the environmental impacts of a plan or program, which includes:

1. The writing of a Strategic Environmental Impact Assessment (SEIA).

2. Public consultation.

3. The consideration of both the SEIA and the relevant public consultation during the decisionmaking process.

4. Information regarding the relevant decision.

It is worth noting at this point that there is a clear differentiation between the SEA JMD and the corresponding SEA Directive. The SEA JMD namely consists of 11 articles and 4 annexes, whereas the SEA Directive consists of 15 articles and 2 annexes, and it is a transposition of the Directive into the measures and particularities of Greek reality. Moreover, in the SEA JMD, we can highlight that:

1. Scoping (Article 3 and Annex I) is explicitly defined, as opposed to the breadth of the scope of the Directive. It also includes specific types of plans and programs, the most prominent of those can be considered: The urban and spatial planning, Community Operational Programs, as well as those co-funded by the EU.

2. The concept of environmental screening is clearly stipulated, and the enactment regarding the associated procedure is specifically established (Article 5 and Annex IV).

3. A specific definition of the environmental report is given (SEIA-article 2), and its content is clearly defined (Article 6 and Annex III).

4. There is no separate article of public consultation. Nevertheless it is more clearly defined (Article 7). The public consultation process involves the transmission of the SEIA to the competent public authorities while it is published to the public concerned.

\subsection{SEA Methodological Approach}

According to Partidario [30], a model is considered strategic when it includes a visualization of long-term goals, flexibility in the management of complex systems, ability to adapt to dynamic environments and conditions, and focus on the crucial elements. SEA exhibits a strategic approach when the definition of the long-term goals, the adoption of courses of action and the application of the necessary resources have all been assured [31]. Within the framework of its "strategic" nature, SEA must, by necessity, ensure that the strategic actions do not exceed the boundaries, beyond which the impacts will cause irreparable damage to the environment [4]. Therefore, when the SEA decisions and procedures are adhered to at a higher level, their reassessment at lower levels is rendered unnecessary, resulting in conservation of time and resources [4]. The strategic programming framework is demonstrated in Figure 1. 


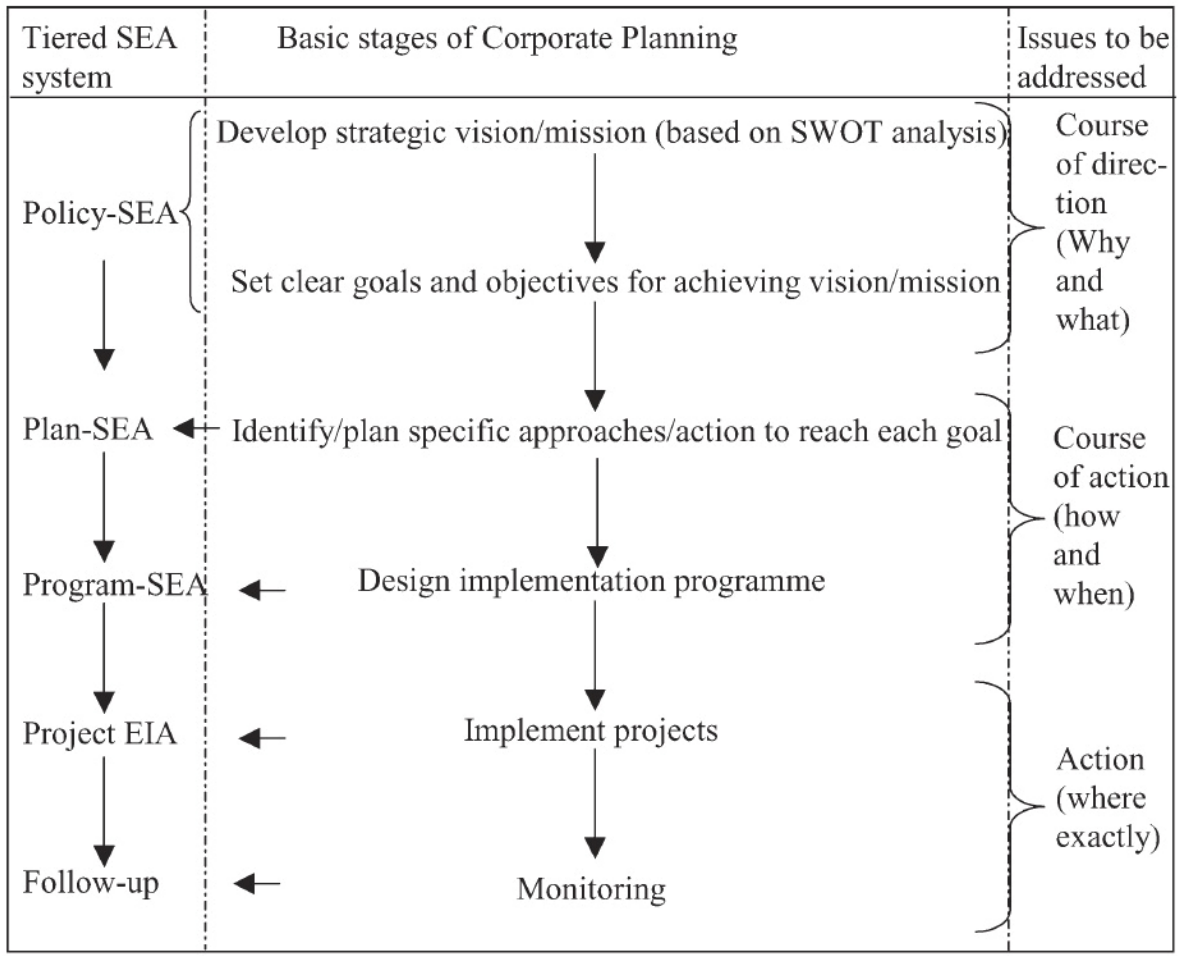

Figure 1. Basic strategic planning model ([32], following [33-35]).

An overview of the bibliography reveals that there is no common reception in the SEA approach. Over the years, various researchers and organizations have suggested SEA types, on the basis of the spatial design and the objective of the evaluation (regional and sectoral policy-[36]), the role played by SEA in the protection of environmental matters during the decision-making process (marginal, compliance, constructive-[37]), the means by which SEA is connected to or interacts with policy-making or planning procedures (single opportunity, parallel, integrated, decision centered-[30]) or based on a general SEA typology (formal, near-equivalent, para-SEA, [38]). In Figure 2, we have decided to present the approach formulated by Noble and Nwanekezie [39], due on the one hand to it being less complex, centered on the fundamental principles of SEA, while on the other reflecting the most recent scientific thought on the means by which SEA will improve strategic decision-making.

Strategic Environmental Assessment

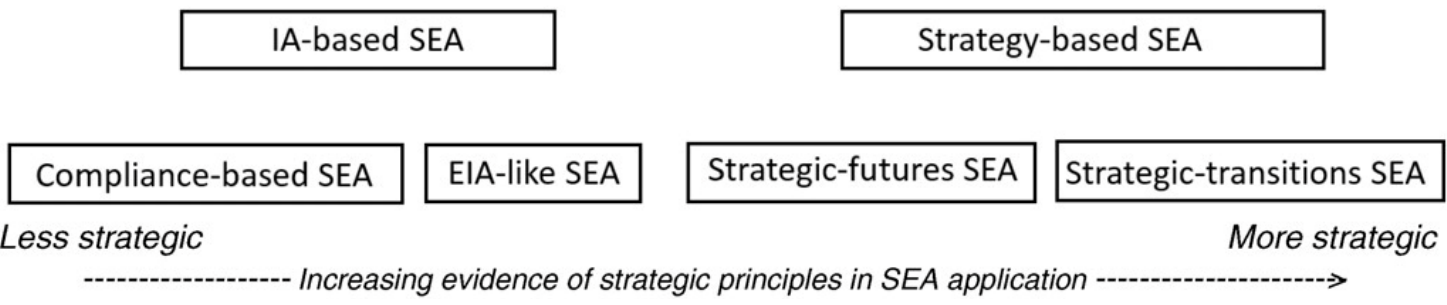

Figure 2. Impact assessment-based and strategic-based conceptualization of SEA [39].

According to the authors, SEA can function within a wide strategic scope, to either a lesser or greater extent. In the former case, SEA is based on predetermined procedures, correspondent to those rooted in EIA. Notable examples are the SEA outlined in European Directive 2001/42/EC and The Canadian CEAA Directive [38]. By contrast, in the latter case, during SEA processes, the focus of the evaluation is centered on the issue. The incentive is to locate the appropriate PPP or a suitable 
alternative strategy, which will provide a resolution to the issue, with the objective of achieving the intended PPP goals [40].

\subsection{SEA Methods and Techniques}

The methods and techniques used in SEA procedures are undefined, in comparison to the exact, practical tools used in other scientific fields [41]. This ambiguity is due to the fact that there are, as of yet, no strictly defined methods and techniques at every step of SEA. Furthermore, the prevailing attitude views these as a collection of tools, of which users are encouraged to select those most suitable for each situation [42].

According to the general prerequisites [43,44], SEA methods and techniques should:

- Be fit for purpose, i.e., they should be able to address key issues and fit into the decisionmaking process.

- Be integrated into the decision-making timetable.

- Allow the integration of various substantive aspects, i.e., various administrations, sectors, and procedures.

- Allow for the accommodation of uncertainties.

- Be transparent, robust, and relevant to the objective and the practices.

- Be understandable to all parties participating in SEA.

- Be cost-effective.

- Offer alternatives, in addition to measures designed to mitigate any negative impacts.

- Allow the comparison of alternatives.

These prerequisites ought to be considered more as general principles, rather than criteria for the selection, in each individual case, of the most suitable SEA methods and techniques. According to Therivel [4], the factors which determine which of these are most appropriate for each individual case are the scale (international, national, regional, local), the "strategic-ness" (policy, plan, program) of the strategic actions, the type of decision, the audience who would use the outputs, the context in which SEA is conducted, the availability of time, resources, personnel, and equipment, as well as the types of data required by the methods and techniques. Finally, a common defining factor is the tradition and mindset of each individual state, researcher, or practitioner.

A large number of methods and techniques is available for use in SEA processes. According to Lee [5], a study carried out in the early 1980s on behalf of two Dutch ministries compiled descriptions of 350 different methods and techniques in North American and Western European literature. Nevertheless, of this wide array, only a small number were utilized in practice [43-45]. Although an in-depth analysis goes beyond the scope of the present paper (see in greater detail [2,4,43,44,46-49]), Table 2 presents methods and techniques which are extensively referenced in international literature, and categorizes them into two modules. In the first (methods and techniques works for), the methods and techniques are determined according to the level and scope of their implementation (PPP, large-small area, land use plan, sectoral plan). In the second (methods and techniques copes with), the categorization pertains to the quality of utilized data (incomplete or not, uncertain or not), their nature (qualitative or quantitative), and the resources required for their processing. 
Table 2. Extent of application of SEA methods and techniques ([44] (p. 351), and own processing based on: [2,4,43,46-49]).

\begin{tabular}{|c|c|c|c|c|c|c|c|c|c|c|c|}
\hline \multirow{3}{*}{ Methods and Techniques } & \multicolumn{11}{|c|}{ Key Situation in Which SEA Methods and Techniques Could Be Used } \\
\hline & \multicolumn{7}{|c|}{ Methods and Techniques Works for } & \multicolumn{4}{|c|}{ Methods and Techniques Copes with } \\
\hline & $\begin{array}{l}\text { Policy } \\
\text { Level }\end{array}$ & Plan Level & $\begin{array}{c}\text { Program } \\
\text { Level }\end{array}$ & Large Area & Small Area & $\begin{array}{l}\text { Land Use } \\
\text { Plan }\end{array}$ & $\begin{array}{l}\text { Sectoral } \\
\text { Plan }\end{array}$ & $\begin{array}{c}\text { Incomplete } \\
\text { Data }\end{array}$ & $\begin{array}{c}\text { Uncertain } \\
\text { Data }\end{array}$ & $\begin{array}{c}\text { Qualitative } \\
\text { Data }\end{array}$ & $\begin{array}{c}\text { Few } \\
\text { Resources }\end{array}$ \\
\hline Checklists & ? & ? & $\sqrt{ }$ & $\sqrt{ }$ & $\sqrt{ }$ & $\sqrt{ }$ & $\sqrt{ }$ & $\sqrt{ }$ & $\sqrt{ }$ & $\sqrt{ }$ & $\sqrt{ }$ \\
\hline Compatibility appraisal & $\sqrt{ }$ & $\sqrt{ }$ & $\sqrt{ }$ & $\sqrt{ }$ & $\sqrt{ }$ & $\sqrt{ }$ & $\sqrt{ }$ & $\sqrt{ }$ & $\sqrt{ }$ & $\sqrt{ }$ & $\sqrt{ }$ \\
\hline Cost-benefit analysis & - & - & $\sqrt{ }$ & $\sqrt{ }$ & $\sqrt{ }$ & $\sqrt{ }$ & $\sqrt{ }$ & - & $\sqrt{ }$ & - & - \\
\hline Ecological footprint analysis & $\sqrt{ }$ & $\sqrt{ }$ & $\sqrt{ }$ & $\sqrt{ }$ & $\sqrt{ }$ & $\sqrt{ }$ & $\sqrt{ }$ & $\sqrt{ }$ & $\sqrt{ }$ & - & $?$ \\
\hline Expert judgment & $\sqrt{ }$ & $\sqrt{ }$ & $\sqrt{ }$ & $\sqrt{ }$ & $\sqrt{ }$ & $\sqrt{ }$ & $\sqrt{ }$ & $\sqrt{ }$ & $\sqrt{ }$ & $\sqrt{ }$ & $\sqrt{ }$ \\
\hline Guiding questions & $\sqrt{ }$ & $\sqrt{ }$ & $\sqrt{ }$ & $\sqrt{ }$ & $\sqrt{ }$ & $\sqrt{ }$ & $\sqrt{ }$ & $\sqrt{ }$ & $\sqrt{ }$ & $\sqrt{ }$ & $\sqrt{ }$ \\
\hline Indicators & $\sqrt{ }$ & $\sqrt{ }$ & $\sqrt{ }$ & $\sqrt{ }$ & $\sqrt{ }$ & $\sqrt{ }$ & $\sqrt{ }$ & $\sqrt{ }$ & $\sqrt{ }$ & $\sqrt{ }$ & $\sqrt{ }$ \\
\hline Land use partitioning anal. & - & ? & $\sqrt{ }$ & $\sqrt{ }$ & $\sqrt{ }$ & ? & $\sqrt{ }$ & $\sqrt{ }$ & - & - & - \\
\hline Life cycle analysis & - & - & $\sqrt{ }$ & $\sqrt{ }$ & $\sqrt{ }$ & - & $\sqrt{ }$ & - & $\sqrt{ }$ & ? & - \\
\hline Literature/case review & $\sqrt{ }$ & $\sqrt{ }$ & $\sqrt{ }$ & $\sqrt{ }$ & $\sqrt{ }$ & $\sqrt{ }$ & $\sqrt{ }$ & $\sqrt{ }$ & $\sqrt{ }$ & $\sqrt{ }$ & $\sqrt{ }$ \\
\hline Matrices & $\sqrt{ }$ & $\sqrt{ }$ & $\sqrt{ }$ & $\sqrt{ }$ & $\sqrt{ }$ & $\sqrt{ }$ & $\sqrt{ }$ & $\sqrt{ }$ & $\sqrt{ }$ & $\sqrt{ }$ & $\sqrt{ }$ \\
\hline Modeling & - & ? & $\sqrt{ }$ & ? & $\sqrt{ }$ & ? & $\sqrt{ }$ & ? & ? & - & - \\
\hline Multi-criteria analysis & - & - & $\sqrt{ }$ & ? & $\sqrt{ }$ & ? & $\sqrt{ }$ & - & $\sqrt{ }$ & $\sqrt{ }$ & ? \\
\hline Network analysis & $\sqrt{ }$ & $\sqrt{ }$ & $\sqrt{ }$ & ? & $\sqrt{ }$ & $\sqrt{ }$ & $\sqrt{ }$ & $\sqrt{ }$ & $\sqrt{ }$ & $\sqrt{ }$ & $\sqrt{ }$ \\
\hline Overlay maps & - & $\sqrt{ }$ & $?$ & - & $\sqrt{ }$ & $\sqrt{ }$ & $\sqrt{ }$ & $?$ & $?$ & ? & ? \\
\hline Participatory methods & $?$ & ? & $\sqrt{ }$ & $?$ & $\sqrt{ }$ & $\sqrt{ }$ & $\sqrt{ }$ & $\sqrt{ }$ & $\sqrt{ }$ & $\sqrt{ }$ & $\sqrt{ }$ \\
\hline Risk assessment & - & ? & $\sqrt{ }$ & ? & $\sqrt{ }$ & $\sqrt{ }$ & $\sqrt{ }$ & ? & $\sqrt{ }$ & $?$ & - \\
\hline Scenario/Sensitivity analysis & $?$ & $\sqrt{ }$ & $\sqrt{ }$ & $\sqrt{ }$ & $\sqrt{ }$ & $?$ & $\sqrt{ }$ & - & $?$ & - & - \\
\hline SWOT analysis & $\sqrt{ }$ & $\sqrt{ }$ & $\sqrt{ }$ & $\sqrt{ }$ & $\sqrt{ }$ & $\sqrt{ }$ & $\sqrt{ }$ & $\sqrt{ }$ & $\sqrt{ }$ & $\sqrt{ }$ & $\sqrt{ }$ \\
\hline Vulnerability analysis & $\sqrt{ }$ & $\sqrt{ }$ & $\sqrt{ }$ & - & $\sqrt{ }$ & $\sqrt{ }$ & $\sqrt{ }$ & $?$ & $\sqrt{ }$ & - & - \\
\hline
\end{tabular}


The first conclusion is that the majority of methods and techniques can be utilized, either comprehensively or in part, at all levels and scales, regardless of the quality of the utilized data and required resources. The column titled Qualitative data, in which the methods and techniques are categorized as either qualitative or quantitative, is indicative of both their potential and their limitations. In particular, the qualitative methods and techniques are applicable at all levels of PPP, with the exception of the multi-criteria analysis, in contrast with numerous quantitative methods and techniques, which cannot be applied at the policy level, such as cost-benefit analysis, modeling, etc. The qualitative methods and techniques are applicable even in cases of incomplete or uncertain data and, due to not requiring specialized equipment, can even be utilized when there are limited available resources. Notable examples are expert judgment, guiding questions, and literature/case review. In other words, the qualitative methods and techniques contribute to improve certain SEA steps, making the process more simple and rapid, require little in the way of equipment, and can utilize both qualitative and quantitative data, while simultaneously taking into account existing political sensitivities. By contrast, the quantitative methods and techniques are, in their majority, time-consuming, complicated, and expensive, due to requiring large volumes of data and specialized equipment. However, they are objective, scientifically sound, and produce comprehensible results, while also being useful for application at the planning and programming level, regardless of extent and design. Notable examples are the cost-benefit analysis and the land use partitioning analysis.

Table 3 distinguishes the methods and techniques depending on the extent to which they are applicable at the various steps of SEA. Due to the fact the SEA Directive, and consequently the SEA JMD, both refer to the EIA-like SEA analysis of the steps of SEA, this was chosen as the means of analysis. The differences between this and the figure of Therivel and Wood [44] lie in the addition of the screening column, which aims to pinpoint every element used in the process of preliminary environmental screening, and in the identify alternatives column, with the objective of identifying all those which define alternatives.

Initially, and in contrast with Table 2, it becomes evident that the majority of the methods and techniques cannot be implemented at every step of SEA. Notable exceptions are the participatory methods, which are applicable, either comprehensively or in part, to the entirety of SEA steps. Furthermore, there are methods and techniques which are applicable to the majority of SEA steps, such as expert judgment, guiding questions, indicators, GIS, etc. The majority of these methods and techniques manage primarily qualitative data, exhibit particular advantages, and are noted for their ease of use. On the other hand, the qualitative methods and techniques, due to their various inherent disadvantages, which were previously described, are not suitable for application at the steps of preliminary environmental screening, description of the current status, and monitoring of environmental impacts. Nevertheless, due to their scientific approach and the objectivity of their results, they are notably effective, and are commonly applicable in the identification, description, and evaluation of the environmental impacts of PPP. Indicative examples of such methods and techniques are cost-benefit analysis, modeling, and scenario/sensitivity analysis. 
Table 3. Methods and techniques applicable at various steps of SEA ([44] (p. 352), and own processing based on: [2,4,43,46-49]).

\begin{tabular}{|c|c|c|c|c|c|c|c|c|c|c|c|}
\hline \multirow{2}{*}{ Methods and Techniques } & \multicolumn{11}{|c|}{ SEA Steps during Which SEA Methods and Techniques Could Be Used } \\
\hline & Screening & $\begin{array}{c}\text { Describe } \\
\text { Baseline/Current } \\
\text { Status }\end{array}$ & $\begin{array}{l}\text { Identify } \\
\text { Impacts }\end{array}$ & $\begin{array}{l}\text { Predict } \\
\text { Impacts }\end{array}$ & $\begin{array}{l}\text { Evaluate } \\
\text { Impacts }\end{array}$ & $\begin{array}{l}\text { Identify } \\
\text { Alternatives }\end{array}$ & $\begin{array}{c}\text { Compare } \\
\text { Alternatives }\end{array}$ & $\begin{array}{c}\text { Identify } \\
\text { Cumulative/Indirect } \\
\text { Impacts }\end{array}$ & $\begin{array}{c}\text { Propose } \\
\text { Mitigation }\end{array}$ & $\begin{array}{c}\text { Public } \\
\text { Participation }\end{array}$ & Monitoring \\
\hline Carrying capacity analysis & - & $\sqrt{ }$ & $\sqrt{ }$ & $\sqrt{ }$ & - & $\sqrt{ }$ & - & $?$ & $\sqrt{ }$ & - & - \\
\hline Checklists & $\sqrt{ }$ & $\sqrt{ }$ & - & $\sqrt{ }$ & $\sqrt{ }$ & - & $\sqrt{ }$ & - & $\sqrt{ }$ & ? & $\sqrt{ }$ \\
\hline Compatibility appraisal & - & - & - & - & - & - & - & - & $\sqrt{ }$ & ? & - \\
\hline Cost-benefit analysis & - & - & $\sqrt{ }$ & $\sqrt{ }$ & $\sqrt{ }$ & $\sqrt{ }$ & $\sqrt{ }$ & - & $\sqrt{ }$ & ? & - \\
\hline Ecological footprint analysis & - & $\sqrt{ }$ & $\sqrt{ }$ & $\sqrt{ }$ & - & $\mathfrak{v}$ & - & $?$ & $\sqrt{ }$ & - & - \\
\hline Expert judgment & $\sqrt{ }$ & $\sqrt{ }$ & $\sqrt{ }$ & $\sqrt{ }$ & $\sqrt{ }$ & $\mathfrak{v}$ & $\sqrt{ }$ & $\sqrt{ }$ & $\sqrt{ }$ & - & $\sqrt{ }$ \\
\hline GIS & $\sqrt{ }$ & $\sqrt{ }$ & $\sqrt{ }$ & $\sqrt{ }$ & $\sqrt{ }$ & - & $\sqrt{ }$ & $\sqrt{ }$ & $\sqrt{ }$ & $\sqrt{ }$ & ? \\
\hline Guiding questions & $\sqrt{ }$ & $\mathfrak{v}$ & $\sqrt{ }$ & $\sqrt{ }$ & $\sqrt{ }$ & $\sqrt{ }$ & $\sqrt{ }$ & $\sqrt{ }$ & $\sqrt{ }$ & - & $\sqrt{ }$ \\
\hline Indicators & $\sqrt{ }$ & $\sqrt{ }$ & $\sqrt{ }$ & $\sqrt{ }$ & $\sqrt{ }$ & $\sqrt{ }$ & $\sqrt{ }$ & $\sqrt{ }$ & $\sqrt{ }$ & - & $\mathfrak{v}$ \\
\hline Land use partitioning anal. & - & - & - & $\sqrt{ }$ & $\sqrt{ }$ & - & ? & $?$ & $\sqrt{ }$ & - & - \\
\hline Life cycle analysis & - & - & $\sqrt{ }$ & - & $\sqrt{ }$ & $\sqrt{ }$ & $\sqrt{ }$ & $\sqrt{ }$ & $\sqrt{ }$ & $\sqrt{ }$ & - \\
\hline Literature/case review & $\sqrt{ }$ & $\sqrt{ }$ & $\sqrt{ }$ & $\sqrt{ }$ & $\sqrt{ }$ & $\mathfrak{v}$ & $\sqrt{ }$ & $\mathfrak{v}$ & $\sqrt{ }$ & - & $\sqrt{ }$ \\
\hline Matrices & $\sqrt{ }$ & - & $\sqrt{ }$ & $\sqrt{ }$ & $\sqrt{ }$ & ? & $\sqrt{ }$ & - & $\sqrt{ }$ & $\sqrt{ }$ & $\sqrt{ }$ \\
\hline Modeling & - & - & $\sqrt{ }$ & $\sqrt{ }$ & ? & $\sqrt{ }$ & $\sqrt{ }$ & ? & $\sqrt{ }$ & - & - \\
\hline Multi-criteria analysis & - & - & - & - & $\sqrt{ }$ & $\mathfrak{v}$ & $\sqrt{ }$ & - & $\sqrt{ }$ & ? & - \\
\hline Network analysis & - & - & $\sqrt{ }$ & $\sqrt{ }$ & ? & - & ? & $\sqrt{ }$ & $\sqrt{ }$ & $?$ & - \\
\hline Overlay maps & $\sqrt{ }$ & $\sqrt{ }$ & $\sqrt{ }$ & $\sqrt{ }$ & $\sqrt{ }$ & - & $\sqrt{ }$ & $\mathfrak{v}$ & $\sqrt{ }$ & $\sqrt{ }$ & ? \\
\hline Participatory methods & ? & $\mathfrak{v}$ & $\sqrt{ }$ & $\sqrt{ }$ & $\sqrt{ }$ & ? & $\sqrt{ }$ & $?$ & $\sqrt{ }$ & $\mathfrak{v}$ & ? \\
\hline Quality of life assessment & ? & ? & $\sqrt{ }$ & $\sqrt{ }$ & $\sqrt{ }$ & - & ? & - & $\sqrt{ }$ & $\mathfrak{v}$ & ? \\
\hline Risk assessment & ? & - & - & $\sqrt{ }$ & $\sqrt{ }$ & - & $\sqrt{ }$ & ? & $\sqrt{ }$ & - & - \\
\hline Scenario/Sensitivity analysis & - & - & - & $\sqrt{ }$ & $\sqrt{ }$ & $\sqrt{ }$ & $\sqrt{ }$ & ? & $\sqrt{ }$ & - & - \\
\hline SWOT analysis & - & - & $\sqrt{ }$ & $\sqrt{ }$ & $\sqrt{ }$ & $\mathfrak{v}$ & $\sqrt{ }$ & - & - & - & - \\
\hline Vulnerability analysis & - & - & $\sqrt{ }$ & - & $\sqrt{ }$ & $\mathfrak{v}$ & $\sqrt{ }$ & - & - & - & - \\
\hline
\end{tabular}




\section{Methodology}

In order to broaden the scope of the research, both primary and secondary sources were utilized. Bibliographical references, as secondary sources, were the basis for the examination of international and Greek practices in the adoption of SEA methods and techniques. Subsequently, an effort was made to gather information relevant to the selection of SEA methods and techniques in Greece from the primary sources. The survey was carried out through the filling out of questionnaires by SEIA practitioners. The final conclusions of the paper comprise and utilize the findings of both the primary and secondary research.

\subsection{Secondary Research Methodology}

A representative sample of SEIA was selected in order to examine the Greek practices in the adoption of SEA methods and techniques. The following selection criteria were implemented:

- Plans and programs which were carried out under the auspices, in particular, of the National Strategic Reference Framework 2014-2020 Operational Programmes, General Urban Plans, Special Spatial Plans, Specific Spatial Development Plans for Public Property, or for Strategic Investments, the development of tourist ports, agriculture, energy, waste transportation, and management.

- Selection of national, regional, and local plans and programs.

- Selection of the most recent, in terms of both date and sector, SEA.

- An effort was made to select the plans and programs which were submitted for the preliminary environmental screening process.

- The methods and techniques were indicated or explicitly located in the various individual SEA steps. Table 4 displays the results of this selection process.

Table 4. Greek SEA plans and programs under consideration.

\begin{tabular}{cc}
\hline No & Strategic Environmental Assessment \\
\hline 1 & National Hazardous Waste Management Plan (March 2016) \\
\hline 2 & Specific Spatial Development Plans for Public Property “Asteras Vouliagmenis” (July 2013) \\
\hline 3 & Specific Spatial Development Plans for Strategic Investments, location “Karapetis” Mykonos Island (June 2019) \\
\hline 4 & Special Spatial Plan for the Thessaloniki Exhibition Centre (January 2019) \\
\hline 5 & Operational Programme Competitiveness Entrepreneurship Innovation 2014-2020 (January 2015) \\
\hline 7 & Exploration and exploitation of hydrocarbons in the “Southwest Crete” and Western Crete marine areas (June 2018) \\
\hline 9 & Modification of the General Urban Plan of the Municipality of Halandri-Attica (April 2019) \\
\hline 10 & General Urban Plan of the Municipal Unit of Kallithea of Rhodes island (April 2016) \\
\hline 11 & New master plan of Marina Vouliagmeni (October 2017) \\
\hline 12 & General Urban Plan of the Municipality of Argithea-Regional Unit of Karditsa (March 2016) \\
\hline 13 & Rural Development Programme 2014-2020 (July 2014) \\
\hline
\end{tabular}

The deeper understanding of the relationship between development and environment led to the worldwide adoption of SEA processes, which resulted in the writing of numerous corresponding environmental surveys over the past several years. In order to better compare Greek and international practices, a representative sample of reports from the EU member states was compiled, due to the common SEA institutional framework, which governs them after the transposal of the SEA Directive. Furthermore, additional focus was placed on the examination of SEA processes in plans and programs at all levels (international, national, regional, and local) and of different objectives. The methods and techniques utilized therein were indicated or explicitly placed in the various distinct SEA steps. Finally, reports 
from open online sources, primarily governmental websites, were also chosen. The aforementioned criteria were also used in this case. The examined reports are depicted in Table 5.

Table 5. European SEA environmental reports under consideration.

\begin{tabular}{cr}
\hline No & Strategic Environmental Assessment \\
\hline 1 & UK Offshore Energy SEA (March 2016) \\
\hline 2 & Derby City Council Local Transport Plan 3 SEA (March 2011) \\
\hline 3 & Adriatic-Ionian Operational Programme 2014-2020 SEA (October 2014) \\
\hline 4 & Transport Development Strategy of the Republic of Croatia 2017-2030 SEA (May 2017) \\
\hline 5 & Cooperation Programme of the Baltic Sea Region 2014-2020 SEA (May 2014) \\
\hline 6 & Polish Nuclear Programme SEA (January 2011) \\
\hline 7 & Clonburris Strategic Development Zone SEA (September 2017) \\
\hline 9 & Westminster City Council Municipal Waste Manager Strategy 2016-2026 SEA (September 2013) \\
\hline 10 & South Lanarkshire Local Development Plan SEA (March 2017) \\
\hline
\end{tabular}

It should be noted that during the critical assessment of the selected samples, the proper or improper utilization of methods and techniques was not examined, nor was the possibility of selection of alternative methods and techniques. Furthermore, we took into account the processes for the determination of the sectors of implementation (screening) and the extent of application (scoping), in the cases where the corresponding reports were available online.

\subsection{Primary Research Methodology}

The objective of the primary research was to document the current situation regarding the selection, adequacy, and implementation of current methods and techniques, as well as the current methodological guidance, through the filling out of questionnaires by practitioners experienced in the composition of SEIA. In total, 14 practitioners filled out the questionnaire, while officials from the competent authority of the Ministry of the Environment and Energy were unable to respond to similar requests, citing their heavy workload. The questions were the following:

- Do you face any difficulties during the composition of SEIA?

- Rate 1 to 10 the severity of each criterion for the selection of methods and techniques during the SEIA composition process: 1. Availability of human resources, 2. availability of financial resources, 3. availability of quantitative or qualitative data, 4. professional experience of practitioner, 5 . scale of implementation of a plan or program, 6 . sector wherein the plan or program is taking place, 7. type of decision, 8 . timeline regarding the completion of the report.

- Do the methods and techniques used in the elaboration of SEIA ensure the following? 1. Be fit for purpose, i.e., they should be able to address key issues and fit into the decision-making process, 2. be integrated into the decision-making timetable, 3. allow the integration of various substantive aspects, i.e., various administrations, sectors, and procedures, 4 . allow for the accommodation of uncertainties, 5 . be transparent, robust, and relevant to the objective and the practices, 6 . be understandable to all parties participating in SEA, 7. be cost-effective, 8 . offer alternatives, in addition to measures designed to mitigate any negative impacts, 9. allow the comparison of alternatives.

- Are there any guidance manuals for the selection of methods and techniques during the SEIA composition process?

- If there are such guidance manuals, have you used them? 
- Do you consider the existing methodological guidance for conducting the SEIA, which is provided by the Greek authorities, sufficient?

- According to your perspective, is the SEA an effective tool for meeting the goals set by environmental legislation? If not, would the utilization of different methods and techniques mitigate any resultant issues?

- To evaluate both the knowledge and the application of the recorded methods and techniques, as well as their application in the respective steps of the SEA, tables were given for completion. These tables summarize all the methods and techniques recorded during the bibliographic review.

\section{Results}

The results of the research, which was carried out based on the previously described methodology, are presented in three parts: Applied methods and techniques on a global level, applied methods and techniques in Greece, and primary research findings.

\subsection{Applied Methods and Techniques on a Global Level}

Following the comprehensive examination of environmental reports in Table 5, a categorization of the SEA methods and techniques by step, according to the frequency of their use, was carried out, as can be observed in Table 6 .

Noteworthy conclusions can be drawn from Table 6. Initially, only a limited number of the methods and techniques referenced in international literature were implemented, ten to be precise. Practitioners therefore tend to utilize methods and techniques which they have already used previously. In other words, their professional experience played a crucial role in the selection of the appropriate methods and techniques.

Out of all the utilized methods and techniques, only the GIS and modelling are capable of processing quantitative data, while the data utilized by the others is primarily qualitative. In other words, practitioners exhibited a clear bias in favor of simple, expedited processes, which can be implemented regardless of the quality and quantity of utilized data, with a minimum of personnel and equipment.

The most frequently used methods and techniques were the expert judgment and the matrices. The former was implemented, for the most part, during the screening and scoping processes, while the second was implemented during the determination, evaluation, and assessment of the immediate, indirect, and cumulative impacts, as well as during the specification of measures designed to mitigate these impacts. Of the remaining methods and techniques, the participatory methods were widely implemented during the determination of the extent and breadth of implementation (scoping), while certain reports, the majority of which were carried out in the United Kingdom, also implemented them in the other SEA steps. The GIS were utilized for the production of maps and composite diagrams, and were widely implemented, in tandem with literature/case review, primarily in the description of the current situation. Finally, the majority of reports included the utilization of indicators in order to track the impacts of the plans and programs.

A point of particular interest is the variation in the number of utilized methods and techniques at each individual SEA step. In particular, only two methods and techniques were utilized during the monitoring of impacts. By contrast, the documented methods and techniques utilized during the steps of determination and evaluation of impacts, and determination and comparison of alternative choices were more numerous; eight and seven, respectively. The notable variation in the utilization of methods and techniques during each individual SEA step indicates that, during the screening process, for example, the almost universal implementation of expert judgments yielded precise, objective results, regardless of the scale, nature, and objective of the plans and programs. This is in contrast with the step of determination and comparison of alternative choices, in which the variety of selected methods and techniques indicates the opposite conclusion. 
Table 6. SEA methods and techniques by step of European SEAs.

\begin{tabular}{|c|c|c|c|c|c|c|c|c|c|}
\hline \multirow[b]{2}{*}{ Methods/Techniques } & \multirow{2}{*}{ Screening } & \multirow{2}{*}{ Scoping } & \multicolumn{7}{|c|}{ SEA Steps } \\
\hline & & & $\begin{array}{c}\text { Describe } \\
\text { Baseline Status }\end{array}$ & $\begin{array}{l}\text { Identify—Predict } \\
\text { Impacts }\end{array}$ & $\begin{array}{l}\text { Evaluate } \\
\text { Impacts }\end{array}$ & $\begin{array}{l}\text { Identify Cumulative/Indirect } \\
\text { Impacts }\end{array}$ & $\begin{array}{c}\text { Identify-Compare } \\
\text { Alternatives }\end{array}$ & $\begin{array}{c}\text { Propose } \\
\text { Mitigation }\end{array}$ & Monitoring \\
\hline Checklists & + & & & & & & & + & \\
\hline Expert judgment & +++ & +++ & & ++ & + & ++ & ++ & ++ & \\
\hline GIS & & & +++ & ++ & + & + & + & & \\
\hline Guiding questions & & + & & + & & & + & & \\
\hline Indicators & & & + & + & & & & & +++ \\
\hline Literature/case review & + & + & +++ & + & & + & & & + \\
\hline Matrices & & & ++ & +++ & +++ & +++ & +++ & ++ & \\
\hline Modeling & & & & & & & + & & \\
\hline Multi-criteria analysis & & & & + & ++ & + & + & + & \\
\hline Participatory methods & + & +++ & & + & + & + & + & + & \\
\hline
\end{tabular}


Finally, during the examination of the methodological guidance for the composition of SEA, it occurred that only half of the examined cases referred explicitly to the use of guidance handbooks. In particular, the reports carried out in the United Kingdom and Ireland presented in detail the guidance documents which were utilized, with the universal application of the manual "A practical guide to the Strategic Environmental Assessment Directive", while the SEA Transport Development Strategy of the Republic of Croatia 2017-2030, which was written in Croatian, contains a general reference to guidance manuals of the European Commission.

\subsection{Applied Methods and Techniques in Greece}

A preliminary point worth noting is that during the examination of selected SEA, it was found that guidance manuals for the selection of the most appropriate methodological approach were directly referred to in only seven cases. The manual "Handbook on SEA for Cohesion Policy 2007-2013" was universally implemented during the processes of particular SEA. The general objective of this manual was the advancement of the utilization of SEA for the incorporation of environmental issues in the plans and programs of the EE "Cohesion Policy" during the period of 2007-2013. Two cases utilized the manual "A practical guide to the Strategic Environmental Assessment Directive", which is a guide for the implementation of SEA in the plans and programs of the United Kingdom that fall within the scope of the SEA Directive. Furthermore, of particular note is the "circular for the observation of Strategic Environmental Analysis of Operational Programmes of Operational Period 2007-2013", issued by the Ministry of Finance and the Economy, which concerns the basic principles, scope, and general organization of the environmental monitoring of Operational Programs. One SEA, that of the Strategic Framework of Transportation Investment, utilized yearly reports which were produced by TERM, established by the European Environmental Service in 2000 with the objective of determining and utilizing the most appropriate indicators for the monitoring of transportation and the environment. However, the aforementioned manuals do not contain a distinct methodological guide for the comprehension and selection of the most appropriate methods and techniques in each separate case. Essentially, their almost exclusive focus is on directions for the compliance with the demands of the SEA Directive. Even though there are references to methods and techniques, these are indicative and refer to only a few of the SEA processes. The remaining SEA exhibited references to an overview of the relevant literature, which includes books and relevant reports prepared for the corresponding plans and programs.

In order to examine and evaluate the utilized SEA methods and techniques of Table 4, they were categorized according to their frequency of use by step, as depicted in Table 7.

The first conclusion which can be drawn from Table 7 is that only 12 of the 23 total documented methods and techniques were implemented in SEA processes in the entirety of the plans and programs. Subsequently, it was observed that the practitioners displayed an evident tendency to choose qualitative methods and techniques, with 10 out of a total of 12 being used for the processing of exclusively qualitative data. The expert judgment occupies a prominent position among them, due to being implemented most frequently and at the majority of SEIA steps. It is, however, of note that in most of the SEIA, this particular method was documented as an assessment provided by members of the team which composed the study who specialized in a particular field (e.g., geology, etc.). There are no references, in any study, to whether a particular technique, such as the Delphi Technique, was utilized in order to produce the assessment, or if this was produced solely based on the training, knowledge, or experience of the individual team members. Accordingly, an equally popular technique was the utilization of risk assessment matrices, primarily in table (or register) form, during the steps of environmental screening, determination, and evaluation of alternative choices, as well as in the evaluation and assessment of environmental impacts. Literature/case review was often utilized, primarily during the steps which required the use of bibliographical data, the most prominent of which was the description of the current situation. Finally, special reference must be made to the participatory methods. Despite the fact that they were not widely implemented in the majority of SEIA, they were 
applied during both the determination of alternative choices and in the selection of the final proposal in the SEIA of local spatial plans (MMP, OCSRP), in tandem with the completion of their first step. In particular, in the General Urban Plan of the Municipal Unit of Kallithea of Rhodes island and the General Urban Plan of the Municipality of Argithea-Regional Unit of Karditsa, the participatory methods included the transmission of the first step of the report to the competent public authorities. This was followed by a concurrent publication for the interested public, both with a relevant post in a specific website and open presentations.

The quantitative methods and techniques are on the opposite end of the frequency of use spectrum. In particular, out of all the documented methods and techniques which process quantitative data, only the GIS and modeling were utilized. The former was utilized during the majority of steps, albeit primarily in the description of the current state of the environment, for the production of maps and composite diagrams. The utilization of the latter, on the other hand, was notably limited in scope, a characteristic example being the use of a model for the population growth of the municipal unit of Argithea until 2031, with the application of various different scenarios during the implementation of the local spatial plan.

According to Table 7, the variation in the number of methods and techniques utilized during each separate SEA step is particularly noteworthy. Only two methods and techniques were selected in both the processes of prevention, mitigation, and treatment of environmental impacts and for their monitoring. In the first case, the expert judgment, which was essentially an assessment produced by the research team, was universally implemented in the SEIA, while in the second the method of indicators, was preferred, in order to ensure the capability of timely discovery and treatment of likely impacts. By contrast, the step of determination and evaluation of alternative choices featured the utilization of no less than seven different methods and techniques. The implementation of various methods and techniques, as well as combinations thereof, during this particular step, demonstrates that each selection of the appropriate methods and techniques directly correlates with factors such as, for example, the sector, the scope of implementation of the plans and programs, etc. Finally, the plans which underwent the environmental screening process, despite utilizing a total of five different methods and techniques, all utilized the compatibility appraisal in combination with the use of matrices.

This methodological approach, i.e., the preference of the practitioners for particular methods and techniques, is substantiated, for the most part indirectly, by a large number of them. Initially, the breadth of differentiation in both the content and the planning level, which is observable in the plans and programs subject to SEA, in addition to the fact that the guidance books describe a wide variety of methods and techniques, without clear instructions, has led practitioners to select a limited number of methods and techniques. Implicitly, the existing knowledge and experience of the practitioners is a crucial criterion in the selection of the methods and techniques, which often supersedes others, such as the scale of implementation of the plan or program, etc.

Accordingly, the evident bias in favor of qualitative, instead of quantitative, methods and techniques, is due to two crucial factors. On the one hand, the immaturity of the plans and programs, due to the lack of detailed characteristics of the projects and activities which comprise them, often makes the quantitative evaluation of environmental changes impossible. On the other hand, the quantitative methods and techniques constitute, for the most part, composite computational tools which require massive volumes of data, as well as specialized personnel and equipment. Essentially, due to the similarity of the quantitative methods and techniques with the EIA approach, their use is made difficult at the SEA level of plans and programs.

To conclude, the breadth of the methods and techniques utilized in the SEA under examination is relatively limited, and is comprised of the most common qualitative methods and a small number of quantitative techniques. In order to achieve the SEA objectives, practitioners selected, according to their own publications, a composite of methods and techniques, i.e., the combined utilization of two or more methods and techniques. This was observed in the steps of specification and evaluation of alternative choices, and in the assessment and evaluation of environmental impacts. 
Table 7. Utilized SEA methods and techniques by key SEA steps.

\begin{tabular}{|c|c|c|c|c|c|c|c|c|c|c|}
\hline \multirow[b]{2}{*}{ Methods/Techniques } & \multirow[b]{2}{*}{ Screening } & \multicolumn{8}{|c|}{ SEIA (Strategic Environmental Impact Assessment) Steps } & \multirow[b]{2}{*}{ Public Consultation } \\
\hline & & General Data & Scoping & $\begin{array}{c}\text { Plan or } \\
\text { Program } \\
\text { Description }\end{array}$ & $\begin{array}{l}\text { Identify-Compare } \\
\text { Alternatives }\end{array}$ & $\begin{array}{l}\text { Describe } \\
\text { Baseline } \\
\text { Status }\end{array}$ & $\begin{array}{l}\text { Identify_-Predict- } \\
\text { Evaluate Impacts }\end{array}$ & $\begin{array}{c}\text { Propose } \\
\text { Mitigation }\end{array}$ & Monitoring & \\
\hline Compatibility appraisal & +++ & & & & & & & & & \\
\hline Checklists & + & & & & & & & & & $\begin{array}{l}\text { stakeholder } \\
\text { stat }\end{array}$ \\
\hline Expert judgment & & & +++ & +++ & + & & + & +++ & + & engagement is \\
\hline GIS & ++ & This step does & + & ++ & + & +++ & + & & & regulated and \\
\hline Guiding questions & & not require a & + & & + & & +++ & & & involves the \\
\hline Literature/case review & & defined & +++ & ++ & & +++ & + & + & & transmission of the \\
\hline Matrices & +++ & methodology for & & + & +++ & + & +++ & & & report to the \\
\hline $\begin{array}{l}\text { Participatory methods } \\
\text { Indicators }\end{array}$ & & its completion & + & & + & & & & +++ & $\begin{array}{l}\text { competent public } \\
\text { authorities while it is }\end{array}$ \\
\hline Modeling & & & & & & + & & & & $\begin{array}{l}\text { authorities while it is } \\
\text { published to the }\end{array}$ \\
\hline Multi-criteria analysis & & & & & ++ & & ++ & & & public concerned. \\
\hline SWOT analysis & +++ & & & + & + & & & & & \\
\hline
\end{tabular}

+++ used in $50 \%$ or more of the examined cases, ++ used in $26-49 \%$ of the examined cases, + used in $25 \%$ or less of the examined cases. 


\subsection{Primary Research Findings}

The research through questionnaires has the objective of enriching the findings of the study. Half of the participants stated that they encountered difficulties in the composition of SEIA, the most commonly encountered of which were the following:

- Difficulty in the specification and categorization of the means of intervention of the plan or program under evaluation.

- Difficulty in the collection of sufficient and reliable data for the description of the current situation of the regions under examination.

- Inadequate specification of alternative choices from the practitioners in charge of drafting the plan documents, resulting in difficulties in the documentation of their environmental impacts.

- Lack of cooperation and direction from the competent authorities with regards to the determination of evaluation criteria for the impacts, the adequacy of available data, the implemented methodology, and the suggested measures of treating the impacts.

- Incomprehensible and often incomplete legislation.

In the composition of a SEIA, the most common criterion in the selection of methods and techniques is the "sector of the plan or program", followed by the "availability of qualitative or quantitative data". The "availability of financial resources" is an equally crucial factor. By contrast, factors of lesser significance are the "study completion timeframe" and "type of decision", while the professional experience of the involved practitioner was a frequent, albeit not decisive, factor in the selection of methods and techniques. Finally, the criteria "scale of implementation of the plan or program" and "availability of human resources" were subject to the most significant divergence of opinions among the participants.

The majority of participants stated that the methods and techniques utilized during the composition of SEIA were appropriate for their purpose. In other words, they were in a position to treat the basic issues which occurred, and were also suited to the decision-making process. Subsequently, the participants considered that the utilized methods and techniques offered adequate alternative choices and effective measures in order to mitigate any negative environmental impacts, while at the same time allowing for the effective comparison between alternative choices. Simultaneously, according to the majority of the participants, the methods and techniques facilitated the incorporation of various substantive environmental aspects. However, there was a number of observations among the participants regarding the shortcomings in their implementation. The majority of the participants believe that the utilized methods and techniques do not allow the effective treatment of uncertainties, are not transparent and relevant to the stated objective, are not comprehensible to all those involved in the SEA process, and finally, are not cost-effective. Finally, the vast majority of participants believe that the utilized methods and techniques contribute to time-consuming processes, resulting in their exclusion from the decision-making timeframe.

As for the existence and utilization of guidance manuals for the selection of methods and techniques during the composition of SEIA, half of the participants consider that these manuals exist, and use them. The remainder of the participants reported that no such manuals exist, at either the national or the European level, as the only guidance comes from the corresponding legislative documents. The guidance manuals used by the participants are documented in Table 8 . 
Table 8. Guidance manuals for the selection of methods and techniques in the composition of SEIA.

\begin{tabular}{|c|c|}
\hline No & Guidance Manuals \\
\hline 1 & $\begin{array}{l}\text { Applying Strategic Environmental Assessment. Good practice guidance for development } \\
\text { co-operation, Organization for Economic Co-operation and Development, } 2006\end{array}$ \\
\hline 2 & $\begin{array}{l}\text { A sourcebook on SEA of transport infrastructure plans and programs, European } \\
\text { Commission, } 2005\end{array}$ \\
\hline 3 & $\begin{array}{l}\text { Environmental assessments of Plans, Programmes and Projects. Rulings of the Court of } \\
\text { Justice of the European Union, European Union, } 2017\end{array}$ \\
\hline 4 & $\begin{array}{l}\text { Guidance on Integrating Climate Change and Biodiversity into Strategic Environmental } \\
\text { Assessment, European Union, } 2013\end{array}$ \\
\hline 5 & $\begin{array}{c}\text { Handbook on SEA for Cohesion Policy 2007-2013, Greening Regional Development } \\
\text { Programmes Network, } 2006\end{array}$ \\
\hline 6 & $\begin{array}{l}\text { Implementation of Directive2001/42 on the assessment of the effects of certain plans and } \\
\text { programs on the environment, European Union, } 2004\end{array}$ \\
\hline 7 & $\begin{array}{l}\text { Opinion of the Committee of the Regions on improving the EIA and SEA Directives, } \\
\text { European Commission, } 2010\end{array}$ \\
\hline 8 & $\begin{array}{c}\text { Strategic Environmental Assessment Better Practice Guide-methodological guidance for } \\
\text { strategic thinking in SEA, Partidario M, } 2012\end{array}$ \\
\hline 9 & $\begin{array}{l}\text { Streamlining environmental assessment procedures for energy infrastructure Projects of } \\
\text { Common Interest, European Union, } 2013\end{array}$ \\
\hline 10 & $\begin{array}{l}\text { Study concerning the application and effectiveness of the SEA Directive, European } \\
\text { Commission, } 2009\end{array}$ \\
\hline 11 & $\begin{array}{l}\text { Study concerning the preparation of the report on the application and effectiveness of the } \\
\text { SEA Directive, European Union, } 2016\end{array}$ \\
\hline 12 & $\begin{array}{l}\text { The Relationship between the EIA and SEA Directives. Final Report to the European } \\
\text { Commission, Imperial College London, } 2005\end{array}$ \\
\hline 13 & $\begin{array}{l}\text { Implementation of Directive 2001/42 “On Strategic Environmental Assessment” in the } \\
\text { preparation of the Operational Programmes for the 2007-2013 programming period, } \\
\text { Ministry of Environment, Spatial Planning and Public Works, } 2006\end{array}$ \\
\hline
\end{tabular}

However, none of the aforementioned documents propose the use of the most effective methods and techniques during SEA procedures. Certain documents, such as the "Handbook on SEA for Cohesion Policy 2007-2013" and the "Sourcebook on SEA of transport infrastructure plans and programmes", offer a more generalized and adaptable methodological approach for the SEIA guidance of particular types of plans and programs, in order for these to conform to the SEA Directive. Furthermore, documents such as the "Study concerning the preparation of the report on the application and effectiveness of the SEA Directive" and "The Relationship between the EIA and SEA Directives", are meant to offer information to the European Commission regarding the progress of the EU member states in the implementation of the SEA Directive, as well as to emphasize the points at which the SEA and EIA Directives overlap. In other words, the aforementioned documents are exclusively studies for the preparation of reports of the European Commission regarding the implementation and efficacy of the SEA Directive.

The results of the study show the inadequacy of the current methodological guidance for the composition of SEIA by the competent authorities in Greece. The lack of methodological guidance from the competent authorities is, according to the participants of the survey, due to the following reasons:

- There is no specialized institutional framework which the competent authorities can refer to for SEA methodology.

- There is a lack of trained personnel at the competent authorities for SEIA monitoring, evaluation, and approval. 
- The observations of the competent authorities are limited to the comprehensiveness of the submitted SEIA file, as well as, occasionally, to the necessary supplemental elements, which usually follow the comments of the relevant competent authorities during public consultation.

- In order to cover the requirements of the JMD 107017/2006, practitioners adapt the methodology of carrying out the SEA according to their own perceptions and scientific and professional background.

Based on these findings, the suggested means of improving the current methodological guidance are the following:

- Incorporation of the conclusions drawn by the European Council reports regarding the implementation of the SEA Directive within the current legislative framework.

- Specialization of the institutional framework with the objective of offering clarifications and suggesting the necessary methods and techniques by step, depending on the sector of the plan or program for which the SEA is being carried out.

- Writing of guidance manuals for the selection of methods and techniques, by either a public body or private entity, according to the updated institutional framework. A particularly useful addition would be the inclusion of representative good practices.

- Reinforcement of the competent authorities with personnel, with concurrent training of current personnel, in order to achieve, on the one hand, substantive monitoring and evaluation of the SEIA being drafted, and on the other, effective monitoring of the environmental impacts from the implementation of the plan or program.

The participants in the survey were given a list (table) with the most frequent methods/techniques referred to in the literature, and were asked to indicate those that they know and those they use during the SEA process. The results are shown in Table 9.

One evident observation is that the majority of the participants were aware of almost the entirety of the SEA methods and techniques. A notable exception was those under the heading "Others", suggested by two of the participants. Asked why they did not utilize all the methods of which they were aware, the participants offered the following answers:

- These methods were not required by the current institutional framework.

- They were deemed unsuitable for implementation in SEA processes.

- There was a lack of necessary data for the implementation of composite analysis methods and techniques.

- There is a lack of financial and human resources for the implementation of specialized methods and techniques.

These reasons correlate with the previous analysis regarding the difficulties faced by practitioners during the composition of SEIA (inadequacy of the current institutional framework, lack of methodological guidance, limited available financial resources).

The analysis of the implemented methods and techniques arrived at equally useful conclusions. Table 9 demonstrates that the majority of the participants only implement 11 of the methods and techniques. The possibility of their utilization, according to the level and scale of implementation, the quality and type of utilized data, as well as the necessary resources for their conclusion, are depicted in Table 10.

According to the above table, the implemented methods and techniques are notably convenient, as, in their majority, they can be applied, either in part or entirely, at all levels and scales of the plans and programs, irrespective of the quality of the utilized data and the necessary resources. Furthermore, most of these methods and techniques, with the exceptions of the GIS and cost-benefit analysis, contribute to simple and expedient processes, do not require specialized equipment, have a limited implementation cost, and can be applied during most of the SEIA steps. A further point of interest is the widespread utilization of the cost-benefit analysis, as it compares the benefits and costs of a 
program based on its monetary worth. However, the composition of SEIA also includes the assessment and evaluation of environmental and social objectives, which are difficult to evaluate by monetary worth. Finally, this particular technique is a time-consuming and costly process, which requires large volumes of data, and is limited to programs and projects, rather than policies and plans.

Table 9. Methods and techniques known and used by the participants.

\begin{tabular}{|c|c|c|c|c|}
\hline \multirow{2}{*}{ Methods/Techniques. } & \multicolumn{2}{|c|}{ Do You Know Them; } & \multicolumn{2}{|c|}{ Do You Use Them; } \\
\hline & Yes & No & Yes & No \\
\hline Carrying capacity analysis & +++ & + & ++ & +++ \\
\hline Checklists & +++ & + & +++ & ++ \\
\hline Compatibility appraisal & ++ & +++ & + & +++ \\
\hline Cost-benefit analysis & +++ & + & +++ & ++ \\
\hline Ecological footprint analysis & +++ & + & ++ & +++ \\
\hline Expert judgment & +++ & ++ & +++ & ++ \\
\hline GIS & +++ & + & +++ & + \\
\hline Guiding questions & +++ & ++ & ++ & +++ \\
\hline Indicators & +++ & + & +++ & + \\
\hline Land use partitioning analysis & +++ & ++ & + & +++ \\
\hline Life cycle analysis & +++ & + & ++ & +++ \\
\hline Literature/case review & +++ & + & +++ & ++ \\
\hline Matrices & +++ & + & +++ & + \\
\hline Modeling & +++ & + & + & +++ \\
\hline Multi-criteria analysis & +++ & + & +++ & + \\
\hline Network analysis & +++ & ++ & + & +++ \\
\hline Overlay maps & +++ & ++ & ++ & +++ \\
\hline Participatory methods & +++ & ++ & +++ & ++ \\
\hline Quality of life assessment & +++ & ++ & ++ & +++ \\
\hline Risk assessment & +++ & + & +++ & ++ \\
\hline Scenario/Sensitivity analysis & +++ & ++ & ++ & +++ \\
\hline SWOT analysis & +++ & + & +++ & ++ \\
\hline Vulnerability analysis & +++ & ++ & + & +++ \\
\hline \multicolumn{5}{|l|}{ Other defined by the participants: } \\
\hline Critical factors & + & +++ & + & +++ \\
\hline Ecosystem services & + & +++ & + & +++ \\
\hline GHG emission calculators & + & +++ & + & +++ \\
\hline Spheres of influence and Ecosystem chains & + & +++ & + & +++ \\
\hline CO2MPARE & + & +++ & + & +++ \\
\hline PEST & + & +++ & + & +++ \\
\hline AKIS & + & +++ & + & +++ \\
\hline
\end{tabular}

+++ identified by $50 \%$ or more of participants, ++ identified by $26-49 \%$ of participants, + identified by $25 \%$ or less of participants.

Table 10. Methods and techniques implemented by the majority of the participants.

\begin{tabular}{|c|c|c|c|c|c|c|c|c|c|c|}
\hline $\begin{array}{l}\text { Methods and } \\
\text { Techniques }\end{array}$ & $\begin{array}{l}\text { Plan } \\
\text { Level }\end{array}$ & $\begin{array}{c}\text { Program } \\
\text { Level }\end{array}$ & $\begin{array}{l}\text { Large } \\
\text { Area }\end{array}$ & $\begin{array}{c}\text { Small } \\
\text { Area }\end{array}$ & $\begin{array}{l}\text { Land Use } \\
\text { Plan }\end{array}$ & $\begin{array}{l}\text { Sectoral } \\
\text { Plan }\end{array}$ & $\begin{array}{c}\text { Incomplete } \\
\text { Data }\end{array}$ & $\begin{array}{c}\text { Uncertain } \\
\text { Data }\end{array}$ & $\begin{array}{l}\text { Qualitative } \\
\text { Data }\end{array}$ & $\begin{array}{c}\text { Few } \\
\text { Resources }\end{array}$ \\
\hline Checklists & + & ++ & ++ & ++ & ++ & ++ & ++ & ++ & ++ & ++ \\
\hline Cost-benefit analysis & & ++ & ++ & ++ & ++ & ++ & & ++ & & \\
\hline Expert judgment & ++ & ++ & ++ & ++ & ++ & ++ & ++ & ++ & ++ & ++ \\
\hline GIS & ++ & ++ & ++ & ++ & ++ & ++ & + & + & + & + \\
\hline Indicators & ++ & ++ & ++ & ++ & ++ & ++ & ++ & ++ & ++ & ++ \\
\hline Literature/case review & ++ & ++ & ++ & ++ & ++ & ++ & ++ & ++ & ++ & ++ \\
\hline Matrices & ++ & ++ & ++ & ++ & ++ & ++ & ++ & ++ & ++ & ++ \\
\hline Multi-criteria analysis & & ++ & + & ++ & + & ++ & & ++ & ++ & + \\
\hline Participatory methods & + & ++ & + & ++ & ++ & ++ & ++ & ++ & ++ & ++ \\
\hline Risk assessment & & + & ++ & + & ++ & ++ & + & ++ & + & \\
\hline SWOT analysis & ++ & ++ & ++ & ++ & ++ & ++ & ++ & ++ & ++ & ++ \\
\hline
\end{tabular}


Table 11 demonstrates the methods/techniques which the participants implement during the composition of SEIA, by step. GIS were the most popular technique, as they were utilized by all of the participants, with the majority thereof utilizing them during the steps of alternative choices, description of the current situation, and assessment and evaluation of impacts. Accordingly, the expert judgment was implemented by the majority of the participants during the steps of prevention, mitigation, and treatment of impacts. The techniques of indicators and literature/case review are particularly noteworthy for their universal application, the former during the monitoring of environmental impacts, and the latter during the description of the current situation. Finally, the matrices and the multi-criteria analysis were equally utilized in the corresponding steps, the most notable of which was the assessment and evaluation of the impacts, where they were utilized by the majority of the participants.

The variation in the number of methods and techniques utilized at each separate SEA step is of particular note. During the monitoring of environmental impacts, almost all the participants utilized indicators in combination with others, such as expert judgment, GIS, etc. Correspondingly, during the description of the current situation, literature/case review, in addition to GIS, was the favored choice of all the participants. The most noteworthy step, however, was that of the assessment and evaluation of impacts, during which the majority of participants utilized GIS, matrices and multi-criteria analysis, in combination with a number of other methods and techniques, such as cost-benefit analysis, checklists, etc.

The next conclusion which can be drawn from Table 11 is that the entirety of the methods and techniques were applied by the participants in the majority of the various SEIA steps. However, it is troubling that certain, particular methods and techniques were utilized by the participants during the step of the general data. We must keep in mind that this is the initial step in the study, which contains broad references to the plan or program under evaluation, the initiation of planning of the plan or program, as well as the practitioner responsible for composing the SEIA. In essence, this step does not require a defined methodology for its completion.

The entirety of the previously presented methods and techniques contribute to composite processes, and require trained, experienced personnel to carry them out; their ineffective implementation may result in erroneous decisions. The aforementioned considerations highlight certain issues regarding the actual, substantive understanding of the utilized methods and techniques by all those involved in SEA processes, and their effective application at each step.

Finally, the study recorded the participants' opinions on whether SEA is an effective process for the achievement of the objectives set in place by environmental legislation. According to the majority of the participants, SEA is indeed an effective process, due to covering the insufficiencies of Greek environmental law regarding the assessment of environmental impacts at the "strategic" level, i.e., at a higher level than that of each individual project. However, in order for SEA to assume a substantive role during the early stage of planning, certain amendments must be made. It is telling that at this point, there is no consensus among the participants. Some of them support that, since the current methods and techniques were drawn from those used in EIA, the utilization of more "strategic" methods and techniques stands to mitigate the problem. The majority of participants, however, believe the current methods and techniques are adequate for the fulfillment of the objectives of SEA, although systematic methodological guidance is required for their more effective utilization, primarily during the processes of assessment, evaluation, treatment, and monitoring of environmental impacts. 
Table 11. Methods and techniques implemented during key SEA steps by the participants.

\begin{tabular}{|c|c|c|c|c|c|c|c|c|c|c|}
\hline \multirow[b]{2}{*}{ Methods/Techniques } & \multirow[b]{2}{*}{ Screening } & \multicolumn{8}{|c|}{ SEIA Steps } & \multirow[b]{2}{*}{ Public Consultation } \\
\hline & & $\begin{array}{l}\text { General } \\
\text { Data }\end{array}$ & Scoping & $\begin{array}{c}\text { Plan or } \\
\text { Program } \\
\text { Description }\end{array}$ & $\begin{array}{l}\text { Identify-Compare } \\
\text { Alternatives }\end{array}$ & $\begin{array}{l}\text { Describe } \\
\text { Baseline } \\
\text { status }\end{array}$ & $\begin{array}{l}\text { Identify_Predict- } \\
\text { Evaluate Impacts }\end{array}$ & $\begin{array}{c}\text { Propose } \\
\text { Mitigation }\end{array}$ & Monitoring & \\
\hline Carrying capacity analysis & + & & + & + & + & + & + & & + & \\
\hline Checklists & ++ & + & + & + & + & + & ++ & + & ++ & \\
\hline Compatibility appraisal & + & & + & & + & & + & & & \\
\hline Cost-benefit analysis & + & & ++ & + & ++ & & ++ & ++ & + & \\
\hline Ecological footprint analysis & + & & & + & + & + & ++ & + & + & \\
\hline Expert judgment & + & + & ++ & + & + & + & ++ & +++ & ++ & \\
\hline GIS & + & + & + & ++ & +++ & +++ & +++ & ++ & ++ & \\
\hline Guiding questions & + & & + & + & & + & + & & + & The process of \\
\hline Indicators & ++ & + & + & & + & ++ & ++ & ++ & +++ & $\begin{array}{l}\text { Ine process of } \\
\text { stakeholder }\end{array}$ \\
\hline Land use partitioning analysis & & + & + & + & + & + & + & + & + & engagement is \\
\hline Life cycle analysis & & & & & + & & ++ & + & + & $\begin{array}{l}\text { engagement is } \\
\text { regulated and involves }\end{array}$ \\
\hline Literature/case review & ++ & + & ++ & + & + & +++ & ++ & ++ & + & the transmission of the \\
\hline Matrices & + & + & + & + & ++ & + & +++ & ++ & + & report to the competent \\
\hline Modeling & & & + & & + & + & ++ & + & + & public authorities while \\
\hline Multi-criteria analysis & + & & + & & ++ & + & +++ & ++ & + & it is published to the \\
\hline Network analysis & + & & + & & + & + & + & + & + & public concerned \\
\hline Overlay maps & + & + & + & + & + & ++ & + & + & + & \\
\hline Participatory methods & + & + & ++ & + & ++ & + & + & + & + & \\
\hline Quality of life assessment & + & & + & + & & + & + & + & + & \\
\hline Risk assessment & & & & & + & & ++ & ++ & + & \\
\hline Scenario/Sensitivity analysis & & & & & + & & + & + & + & \\
\hline SWOT analysis & + & + & + & + & ++ & + & ++ & + & + & \\
\hline Vulnerability analysis & & & + & & + & + & ++ & + & + & \\
\hline Other: PEST, AKIS & & & + & + & & & & & & \\
\hline
\end{tabular}

+++ filled by $50 \%$ or more of participants, ++ filled by $26-49 \%$ of participants, + filled by $25 \%$ or less of participants. 


\section{Discussion and Conclusions}

Based on the findings of the preceding study, the Greek and international practices are comparatively evaluated, taking into account two aspects: Methodological guidance for the composition of SEA, and applied methods and techniques. Subsequently, the conclusions of the primary research regarding both the effectiveness of SEA in Greece and the utilization of methods and techniques will be stated, and certain proposals will be suggested for the elimination of recorded anomalies.

The examination of the methodological guidance for the composition of SEA yielded common results in both international and Greek practice. In particular, the study of representative examples from both Greece and abroad demonstrated that in only half of the examined cases there was a clear reference to the utilized guidance documents, while primary research revealed that only half of the participating practitioners were aware of, and utilized, guidance manuals.

Furthermore, it was found that certain guidance manuals were utilized with greater frequency by the practitioners. At the international level, for which we have detailed information only of those applied in the United Kingdom and Ireland, the "A practical guide to the Strategic Environmental Assessment Directive" is by far the most popular guide. Correspondingly, in Greece, the "Handbook on SEA for Cohesion Policy 2007-2013", is universally applied, while "A practical guide to the Strategic Environmental Assessment Directive" and "Sourcebook on SEA of transport infrastructure plans and programmes" were also regularly consulted. A defining element of the methodological inadequacy in Greece is the lack of any domestic guidance manual, with the guidelines for the composition of SEA being determined by the provisions of JMD 107017/2006 and certain circulars that have been issued.

As was mentioned previously, the aforementioned guidance documents offer a general, flexible methodological approach for the guidance of SEA, with the objective of conforming to the SEA Directive. However, even though some of these documents offer instructions for each individual SEA step, they do not include exact, substantive methodological guidance for the comprehension and selection of the most appropriate methods and techniques for each individual SEA step. Additionally, it appears that certain documents, which were discovered in the international SEA practices (e.g., United Kingdom SEA), have been adapted to the requirements and demands of each state, precluding the possibility of their utilization by other EU member states.

As for the applied SEA methods and techniques, the study demonstrated that similar methods and techniques are utilized in practice, both internationally and in Greece, with their number being from 10 to 12. A number of factors influence the selection of particular methods and techniques by the practitioners of the states in which the SEA Directive has been transposed. First, the common legislative framework which governs the states, which adopts an EIA-like SEA approach, is a crucial factor, due to demanding particular methods and techniques. Similarly, the practitioners utilized specific guidance documents, which recommended a similar approach in the selection of methods and techniques, resulting in the utilization of comparable criteria, as these were established in the course of the primary research, for the selection of the most appropriate methods and techniques during SEA processes.

The majority of applied methods and techniques contribute to simple and expedited processes, process qualitative data, and can be implemented even in cases of inadequate or uncertain information, while, due to not requiring specialized equipment, they can be utilized even when financial resources are limited (with expert judgment, matrices, literature/case review, indicators as notable examples). Of the quantitative methods and techniques, GIS was most widely used in the production of maps and composite diagrams.

There are also evident similarities in the variation of the number of utilized methods and techniques at each individual SEA step. The steps of assessment and evaluation of impacts, and of alternative, saw the use of the widest variety of methods and techniques of those documented in the selected case studies, with the majority of both Greek and European practitioners utilizing risk assessment matrices of primarily table form, in combination with the other methods and techniques. By contrast, 
the fewest methods and techniques were utilized during the step of monitoring of environmental impacts, with the universal utilization of environmental indicators.

To sum up the findings of the primary study, Greek practitioners encounter significant difficulties during SEA processes, the most important of which have to do with: (a) Incomprehensible, incomplete legislation, (b) difficulties in the determination and categorization of the types of intervention of the plan or program under examination, (c) difficulties in the collection of sufficient and reliable data, (d) insufficient definition of alternative by the practitioners in charge of drafting the plan documents, and (e) lack of cooperation and guidance by the competent authorities.

The current methodological guidance has been deemed inadequate. This particular shortcoming is observable primarily in the lack of a specialized institutional framework for SEA methodology and the lack of trained personnel at the competent authorities. This results in, on the one hand, comments being expressed by the latter being limited to the comprehensiveness of the submitted SEIA file, and on the other the methodology being specialized on the initiative of the practitioners themselves, in order to cover the requirements of the JMD 107017/2006.

Despite the applied methods and techniques being considered appropriate for their objective, the lack of methodological guidance and the selection criteria for the SEA methods and techniques which the practitioners themselves set in place, as they were presented in Section 4.3, result in the selection of methods and techniques which cannot treat uncertainties, are characterized by a lack of transparency, and are not always relevant to the stated objective, while also being incomprehensible to all those involved in the SEA, and lacking cost-effectiveness. The preference for qualitative rather than quantitative methods and techniques is correlated, on the one hand, with the immaturity of the plans and programs, and on the other, with the complexity of the quantitative methods, which, as a rule, contribute to more time-consuming processes, and require the processing of large volumes of data by specialized personnel utilizing specialized equipment.

The more than ten years of experience from the introduction of the SEA Directive into Greek environmental law demonstrate the coverage of a significant deficiency regarding the assessment of environmental impacts during the early planning stage of plans and programs. Despite the fact that SEA has been recognized by the majority of the Greek practitioners who participated in the study as an effective environmental process, the extent to which this particular process has contributed to the goal of sustainable development remains a controversial issue. The ambiguity which, due exactly to its "strategic" nature, characterizes SEA, the current legislation, which, by contrast, requires the adherence to processes based on the corresponding practices of EIA, and the lack of methodological guidance, constitute a tripartite obstacle practitioners have not been able to bypass with the application of the current methods and techniques.

In order to mitigate existing anomalies, crucial changes must be made. These must be immediately applicable, without requiring complex, time-consuming and, primarily, bureaucratic procedures. Within this framework, our suggestion is the determination of technical specifications for the SEA process by sector for plans or programs, in addition to the writing of guidance manuals by sector for plans or programs, as extensions of the technical specifications of the corresponding sector. Furthermore, we propose the writing of a manual of indicators for the recording and monitoring of environmental impacts from the implementation of the plans or programs, by sector and type of plan or program, in addition to training courses for the personnel of the authorities responsible for the planning of plans and programs and the general monitoring and approval of environmental reports and practitioners, in the implementation of the most appropriate methods and techniques during SEA processes. Finally, we propose the broader utilization of participatory methods, such as the citizens' jury, during the step of evaluation of alternative of the plan or program.

Author Contributions: Conceptualization, A.T.; methodology, A.T. and A.S.; research conduction, data collection and analysis, visualization, A.S.; research supervision, A.T.; writing, review \& editing of the paper, A.S. and A.T. All authors have read and agreed to the published version of the manuscript.

Funding: This research received no external funding. 
Conflicts of Interest: The authors declare no conflict of interest.

\section{References}

1. Sadler, B.; Aschemann, R.; Dusik, J.; Fischer, T.; Partidario, M.; Verheem, R. Handbook of Strategic Environmental Assessment; Earthscan: London, UK, 2011.

2. OECD (Organisation for Economic Co-operation and Development). Applying Strategic Environmental Assessment: Good Practice Guidance for Development Co-operation; OECD Publishing: Paris, France, 2006; Available online: https://www.oecd.org/environment/environment-development/37353858.pdf (accessed on 10 March 2020).

3. Noble, B.F.; Storey, K. Towards a structured approach to strategic environmental assessment. J. Environ. Assess. Policy Manag. 2001, 3, 483-508. [CrossRef]

4. Therivel, R. Strategic Environmental Assessment in Action; Earthscan: London, UK, 2004.

5. Lee, N. Bridging the gap between theory and practice in integrated assessment. Environ. Impact Assess. Rev. 2006, 26, 57-78. [CrossRef]

6. Noble, B.F.; Gunn, J.; Martin, J. Survey of current methods and guidance for strategic environmental assessment. Impact Assess. Proj. Apprais. 2012, 30, 139-147. [CrossRef]

7. Zagorianakos, E. An ex-ante appraisal of the possible implementation of the proposed directive on strategic environmental assessment (SEA) in England and Greece. Plan. Pract. Res. 1999, 14, 445-465. [CrossRef]

8. Zagorianakos, E. Athens 2004 olympic games' transportation plan: A missed opportunity for strategic environmental assessment (SEA) integration? J. Transp. Geogr. 2004, 12, 115-125. [CrossRef]

9. Partidário, M.R. (Ed.) Perspectives on Strategic Environmental Assessment, 1st ed.; CRC Press: New York, FL, USA, 1999.

10. Fundingsland Tetlow, M.; Hanusch, M. Strategic environmental assessment: The state of the art. Impact Assess. Proj. Apprais. 2012, 30, 15-24. [CrossRef]

11. Lee, N.; Walsh, F. Strategic environmental assessment: An overview. Proj. Apprais. 1992, 7, 126-136. [CrossRef]

12. Bina, O. A critical review of the dominant lines of argumentation on the need for strategic environmental assessment. Environ. Impact Assess. Rev. 2007, 27, 585-606. [CrossRef]

13. Sadler, B.; Verheem, R. Conclusions and Recommendations of the International SEA Effectiveness Study. In Proceedings of the 16th Annual Meeting of the International Association for Impact Assessment (IAIA), Estoril, Portugal, 17-23 June 1996.

14. UNECE (United Nations Economic Commission for Europe). Protocol on Strategic Environmental Assessment to the Convention on Environmental Impact Assessment in Transboundary Context. 2003. Available online: https://www.unece.org/fileadmin/DAM/env/eia/documents/legaltexts/protocolenglish.pdf (accessed on 10 March 2020).

15. Peterson, K.; Kose, M.; Uustal, M. Screening decisions concerning the likely impacts of plans and projects on natura 2000 sites. J. Environ. Assess. Policy Manag. 2010, 12, 185-214. [CrossRef]

16. Kassios, K.; Lamprou, M. Distinction Levels of Environmental Impact Assessment Procedures (EIA) and Strategic Environmental Assessment (SEA); National Technical University of Athens: Athens, Greece, 2004; Available online: https://www.hydro.ntua.gr/2004-05-21-conference/kassios-lambrou-text.pdf (accessed on 10 March 2020). (In Greek)

17. Kläne, C.; Albrecht, E. Purpose and Background of the European SEA Directive. In Implementing Strategic Environmental Assessment. Environmental Protection in the European Union; Schmidt, M., Joao, E., Albrecht, E., Eds.; Springer Science \& Business Media: Berlin/Heidelberg, Germany, 2005; Volume 2, pp. 15-29.

18. Arce-Ruiz, R.M.; Soria-Lara, J.A.; González-Del-Campo, A. SEA effectiveness in Spain: Insights from practice. Impact Assess. Proj. Apprais. 2019, 37,327-333. [CrossRef]

19. Baresi, U.; Vella, K.J.; Sipe, N.G. Bridging the divide between theory and guidance in strategic environmental assessment: A path for Italian regions. Environ. Impact Assess. Rev. 2017, 62, 14-24. [CrossRef]

20. Bragagnolo, C.; Geneletti, D. Dealing with land use decisions in uncertain contexts: A method to support Strategic Environmental Assessment of spatial plans. J. Environ. Plan. Manag. 2014, 57, 50-77. [CrossRef]

21. Campagna, M.; Di Cesare, E.A.; Matta, A.; Serra, M. Bridging the Gap between Strategic Environmental Assessment and Planning: A Geodesign Perspective. Int. J. E-Plan. Res. 2018, 7, 34-52. [CrossRef] 
22. Lai, S.; Leone, F.; Zoppi, C. Strategic Environmental Assessment and Enhancement of Ecosystem Services: A Study concerning Spatial Planning in Sardinia (Italy). In Urban Planning and Renewal; Wolfe, M., Ed.; Nova Science Publishers, Inc.: New York, NY, USA, 2018; pp. 61-83.

23. Lamorgese, L.; Geneletti, D. Sustainability principles in strategic environmental assessment: A framework for analysis and examples from Italian urban planning. Environ. Impact Assess. Rev. 2013, 42, 116-126. [CrossRef]

24. García, J.L.M.I. Strategic environmental assessment for metropolitan plans of coastal areas. The case of Valencia. Int. J. Sustain. Dev. Plan. 2017, 12, 1272-1281.

25. Rega, C.; Bonifazi, A. Strategic Environmental Assessment and spatial planning in Italy: Sustainability, integration and democracy. J. Environ. Plan. Manag. 2014, 57, 1333-1358. [CrossRef]

26. Rega, C.; Singer, J.P.; Geneletti, D. Investigating the substantive effectiveness of Strategic Environmental Assessment of urban planning: Evidence from Italy and Spain. Environ. Impact Assess. Rev. 2018, 73, 60-69. [CrossRef]

27. Chaker, A.; El-Fadl, K.; Chamas, L.; Hatjian, B. A review of strategic environmental assessment in 12 selected countries. Environ. Impact Assess. Rev. 2006, 26, 15-56. [CrossRef]

28. Psaila, A.; Statha, T. Strategic Environmental Assessment: A New Institution. In Proceedings of the Electronic Proceedings of the International Exhibition and Conference on Environmental Technology, Athens, Greece, 3-6 February 2005; Technical Chamber of Greece: Athens, Greece. Available online: http://library.tee.gr/digital/m2045/m2045_psaila.pdf (accessed on 10 March 2020). (In Greek).

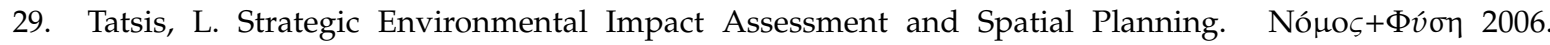
Available online: https://nomosphysis.org.gr/10606/stratigiki-ektimisi-periballontikon-epiptoseon-kaixorikos-sxediasmos-septembrios-2006/ (accessed on 10 March 2020). (In Greek).

30. Partidário, M.R. Strategic Environmental Assessment Better Practice Guide: Methodological Guidance for Strategic Thinking in SEA. Portuguese Environment Agency and Redas Energeticas Nacionais, Lisbon. Available online: http://www.civil.ist.utl.pt/shrha-gdambiente/SEA_Guidance_Portugal.pdf (accessed on 10 March 2020).

31. Noble, B.F. Strategic environmental assessment: What is it? \& what makes it strategic? J. Environ. Assess. Policy Manag. 2000, 2, 203-224.

32. Marshall, R.; Fischer, T.B. Regional electricity transmission planning and SEA: The case of the electricity company ScottishPower. J. Environ. Plan. Manag. 2006, 49, 279-299. [CrossRef]

33. McNamara, C. Strategic Planning (in Nonprofit or For-Profit Organizations). 2002. Available online: http://wk.ixueshu.com/file/76c00f2a9720734f.html (accessed on 10 March 2020). (as referenced in [20]).

34. Fischer, T.B. Lifting the fog on SEA-Towards a categorization and identification of some major SEA tasks: Understanding policy-SEA, plan-SEA and programme-SEA. In Environmental Assessment in the Nordic Countries; H. Bjarnadóttir, H., Ed.; Nordregion: Stockholm, Sweden, 2000; pp. 39-46.

35. Roberts, P. Environmentally Sustainable Business-A Local and Regional Perspective; Paul Chapman Publishing Ltd.: London, UK, 1995.

36. World Bank. Sectoral Environmental Assessment. Environmental Assessment Sourcebook Update 4; World Bank: New York, NY, USA, 1993; Available online: http://documents.worldbank.org/curated/en/256691468740431408/ pdf/multi0page.pdf (accessed on 10 March 2020).

37. Partidário, M.R. Does SEA change outcomes? Discussion paper No. 2009/31. In 18th International Transport Research Symposium; Forum, I.T., Ed.; OECD/ITF: Paris, France, 2009; Available online: https:/www.oecd-ilibrary.org/docserver/5kmmnc5ln3r0-en.pdf?expires=1583926903\& $\mathrm{id}=\mathrm{id} \&$ accname $=$ guest\&checksum $=61$ C578BEB043AD7CA345167421B44B9F (accessed on 10 March 2020).

38. Dalal-Clayton, B.; Sadler, B. Strategic Environmental Assessment: A Sourcebook and Reference Guide to International Experience; Earthscan: London, UK, 2005.

39. Noble, B.; Nwanekezie, K. Conceptualizing strategic environmental assessment: Principles, approaches and research directions. Environ. Impact Assess. Rev. 2017, 62, 165-173. [CrossRef]

40. Partidário, M.R. Scales and associated data-What is enough for SEA needs? Environ. Impact Assess. Rev. 2007, 27, 460-478. [CrossRef]

41. Liou, M.L.; Yeh, S.C.; Yu, Y.H. Reconstruction and systemization of the methodologies for strategic environmental assessment in Taiwan. Environ. Impact Assess. Rev. 2006, 26, 170-184. [CrossRef]

42. Brown, A.L.; Thérivel, R. Principles to guide the development of strategic environmental assessment methodology. Impact Assess. Proj. Apprais. 2000, 18, 183-189. [CrossRef] 
43. Fischer, T.B. Theory and Practice of SEA: Towards a More Systematic Approach; Earthscan: London, UK, 2007.

44. Therivel, R.; Wood, G. Tools for SEA. In Implementing Strategic Environmental Assessment. Environmental Protection in the European Union; Schmidt, M., Joao, E., Albrecht, E., Eds.; Springer Science \& Business Media: Berlin/Heidelberg, Germany, 2005; Volume 2, pp. 349-362.

45. Fischer, T.B. Strategic Environmental Assessment in Transport and Land Use Planning; Earthscan: London, UK, 2002.

46. Bell, S.; Morse, S. Sustainability Indicators: Measuring the Immeasurable? 2nd ed.; Routledge: London, UK, 2012.

47. Finnveden, G.; Nilsson, M.; Johansson, J.; Persson, Å.; Moberg, Å.; Carlsson, T. Strategic environmental assessment methodologies-Applications within the energy sector. Environ. Impact Assess. Rev. 2003, 23, 91-123. [CrossRef]

48. Dusík, J.; Jurkeviciute, A.; McGuinn, J. Handbook on SEA for Cohesion Policy 2007-2013; Greening Regional Development Programmes Network: Exeter, UK, 2006.

49. Rauschmayer, F.; Risse, N. A framework for the selection of participatory approaches for SEA. Environ. Impact Assess. Rev. 2005, 25, 650-666. [CrossRef]

(C) 2020 by the authors. Licensee MDPI, Basel, Switzerland. This article is an open access article distributed under the terms and conditions of the Creative Commons Attribution (CC BY) license (http://creativecommons.org/licenses/by/4.0/). 